\title{
Effects of film coating materials on the quality of postharvest 'Sanh' orange fruits (Citrus nobilis var. Typica) during storage
}

\author{
Thach A. Nguyen*, \& Ngan T. Nguyen \\ Department of Agriculture and Food Technology, Tien Giang University, My Tho, Vietnam
}

ARTICLE INFO
Research Paper
Received: September 28, 2018
Revised: November 16, 2018
Accepted: December 18, 2018
Keywords
Coating
PVC
'Sanh' orange
TSS
Weight loss
*Corresponding author
Nguyen Ai Thach
Email: nguyenaithach2001@gmail.com

\begin{abstract}
Postharvest orange fruit coating is an effective method to replace natural waxes which lost during washing and handling. The coatings can reduce water loss and impart gloss to the fruit. In this study, the oranges were stored at room temperature $\left(30 \pm 2{ }^{0} \mathrm{C}\right)$ with five coating materials: polyethylene $(\mathrm{PE})$, and polypropylene (PP) bags, polyvinyl chloride (PVC) film, Citra Shine preservatives and 1\% chitosan and the control were used. Some typical nutritional values and weight loss were determined during storage time. Research results show that PVC coated 'Sanh' oranges could be prolonged their shelf life up to 25 days with low damage ratios $(7.10 \%$, lower than other bags) which were acceptable in appearance with green peel color. Ascorbic acid content still maintained at a high level $(12.32 \mathrm{mg} / 100 \mathrm{~g})$, and weight loss relatively low (13.91\%). Moreover, $\mathrm{pH}(3.77)$ and TSS (9.70) values did not significantly change during storage time.
\end{abstract}

Cited as: Nguyen, T. A., \& Nguyen, N. T. (2018). Effects of film coating materials on the quality of postharvest 'Sanh' orange fruits (Citrus nobilis var. Typica) during storage. The Journal of Agriculture and Development 17(6), 63-71.

\section{Introduction}

'Sanh' orange (Citrus nobilis var. Typica) is the most popular grown fruit tree in the Mekong Delta. It is made up of soft texture, the fresh quality, juicy, light sweet flavor, and high nutrious value that are very important in human diet since it contains essential vitamins. 'Sanh' orange is a non-climateric fruit, and has a long shelf-life compared to other types of citrus, thus there is a potential for export markets. During the preservation of postharvest 'Sanh' orange, besides the effective of low temperature or cold storage in which is known as one of the most effective method of prolonging the postharvest life of fresh produce and slows down ripening, retards water loss, reduces decay and enhances visual quality, the utilization of synthetic films coating on fruits such as polyethylene (PE), polypropylene (PP), polyvinyl chloride (PVC), chitosan,... (Trout et al., 1952; Bramlage, 1986; Drake \& Nelson, 1990) was considered as one of several treatments developed to maintain the quality of products and reduce the post harvest decay. However, each fruit has own features (respiratory intensity, ethylene production, etc.), and this characteristics alter at different maturity period and in different environmental conditions (temperature and moisture). Porat et al. (2004) indicated that citrus was relatively hard to decay and can be stored for 6 8 days. Nevertheless, the varying degrees damage will be limited and lost due to commercial quality spoilage in the preservation of postharvest. Modifying the internal atmosphere in packaging and using coating films reduced effectively the injuried chilling when the types of different damage 
to the left shell are not related to the cooling as hatching, fallow, wilting and ageing (Wilson \& Wisniewski, 1989; Baldmin et al., 1995). Preserving 'Valencia' orange by using coatings of candelilla in the combination with PE packaging, was stored at $15-25^{\circ} \mathrm{C}$ that retained its hamonious taste after 9 - 16 days during storage (Hagenmaier \& Shaw, 2002). In addition, 'Sanh' orange trees usually flowers in the crop, therefore, the quantity of 'Sanh' orange is so large in the harvest that consumers can not be utilized in the short term. Thus, determining the appropriate preservation for 'Sanh' orange is too necessary in order to serve consumers in the long run as well as to supply raw materials for processing and export. The aim of this study is to characterize the effects of some coating applications on the quality changes, both physically and nutritionally on 'Sanh' orange at the room temperature storage.

\section{Materials and Methods}

\subsection{Materials}

Freshly 'Sanh' oranges were harvested in Tam Binh district, Vinh Long province at 7.5 months after flowering. The fruit was mature and ready for harvest at the orchard at 8 - 10 A.M, and 'Sanh' orange garden has been stopped spraying for 10 days before harvest. Fruits were selected for uniformity in maturity, shape, size, free of physical damage, and the average weight about 200 $250 \mathrm{~g}$.

\subsection{Experiments}

'Sanh' orange was washed by scrubbing gently the fruit surface in clean water to eliminate dirty on the shell, then dried with a soft towel in order to avoid the damage of its shell. Nextly, dip 'Sanh' oranges in a $0.04 \%$ chlorine solution for five minutes to demolish fungi on the surface. After five minutes, fruits were then dried naturally and ready to be used for the experiments. PE, PP and PVC packaging were purchased at local market in Viet Nam (produced by Tan Bach Dat Produce Trading Import Export Company Limited). Characteristics of some plastic packages used in this study: PE is flexible, durable and tear-resistant. A PP bag is nontoxic and high clarity, crystal clear bag. It provides a highly protective barrier against moisture and vapors. These poly bags delay evaporation and dehydration to preserve freshness and taste of packaged foods. PVC is non-toxic, light weight, good mechanical strength and toughness. It is resistant to vapors, chemical rotting, corrosion, shock and abrasion. Fruits were divided into six groups. Each group (sixteen fruits) was treated by different treatments including:

- Control: uncoated (CT).

- Fruits were wrapped with PE bag (one fruit/bag - size $15 \mathrm{~cm} \times 20 \mathrm{~cm}$, chisel five holes, hole diameter $1 \mathrm{~mm})(\mathrm{PE})$.

- Fruits were wrapped with PP bag (one fruit/bag size $15 \mathrm{~cm}$ x $20 \mathrm{~cm}$, unperforated) (PP).

- Fruits were wrapped a layer of PVC carefully (12.5 $\mu \mathrm{m}$ thick) pressed against the left shell (PVC).

- Fruits were coated into Citra Shine (ingredients: natural resins, fatty acid, polyethylene, casein, ammonium hydroxide $25 \%$, pH 9-9.5, Cerexagri, Italy) $50 \%$ emulsion for 30 seconds and then take out (CITRA).

- Fruits were coated into 1\% chitosan (powder made from shrimp shells, $\geq 75 \%$ (deacetylated), a bulk density of $0.15-0.3 \mathrm{~g} / \mathrm{cm}^{3}$, Merck) solution for 30 seconds and then take out (CHITO). The experiments were undertaken in four replications and each research unit was four fruits. All treated fruits were monitored at room temperature $(30 \pm$ $2^{0} \mathrm{C}$ ) and relative humidity $(\mathrm{RH}) 60 \pm 5 \%$ for the quality characteristics.

\subsection{Physico-chemical analyses}

The chemico-physical analysis of the 'Sanh' orange was conducted in triplicates. Ascorbic acid content was analyzed by Association of Official Agricultural Chemists standard (AOAC, 2004). Accordingly, orange pulb samples $(5 \mathrm{~g})$ were extracted in $20 \mathrm{~mL}$ of $1 \% \mathrm{HCl}$ using a chilled pestle and mortar, and then the homogenate was filtered. The juice pulp in $100 \mathrm{~mL}$ of distilled water was titrated with previously prepared $20 \mathrm{~mL}$ aliquot of standardized $0.001 \mathrm{~N}$ dichloroindophenol solution.

Grind about fifty gram orange pulp in a blender or pestle and mortar, transfer to a $100 \mathrm{~mL}$ beaker. Total soluble solids (TSS-oBrix) and $\mathrm{pH}$ value was determined by using a refractometer (Model Atago Digital DBX-5) and digital pH meter (Model PHS-2F), respectively.

The color of fruit peel is frequently determined at nine points randomly distributed on the equa- 
torial region of a fruit by using Minolta colorimeter (Model CR-300, N.J.), with three fruits for each replicate and taking the average. This practice can lead to biased results because these points represent the equatorial region only and not the total area of the fruit peel.

Weight loss (\%) was expressed as the percentage decrease in fruit weight, using the following formula: $\mathrm{L}(\%)=\left[\left(\mathrm{M}_{\mathrm{i}}-\mathrm{M}_{\mathrm{f}}\right) / \mathrm{M}_{\mathrm{i}}\right] \times 100$, with $\mathrm{Mi}$ being the initial weight $(\mathrm{g})$ and Mf being the fruit weight after an indicated period of storage $(\mathrm{g})$.

Incidence of fruit diseases damage was a determined as percentage of the number of decayed fruits from the initial number after an indicated period of storage.

The rate of stem loss $=$ (total number of pods/total number of observations) $\times 100$.

\subsection{Statistical analysis}

The data in this study was carried out using SPSS software (version 2011). Analysis of variance (ANOVA) evaluated differences between treatments. A value $\left({ }^{*} P<0.05,{ }^{* *} P<0.01\right)$ was considered statistically significant for comparison by Duncan's method. The means and standard deviations were also caculated and plotted using Microsoft Excel software 2003 (Microsolft, USA).

\section{Results and Discussion}

\subsection{Weight loss (\%)}

The results in Figure 1 showed that percentage weight loss of 'Sanh' orange increased with the storage period progressed. The percentage weight loss between samples had different significance $(P<0.05)$ during 30 days of storage. After 15 days of storage, the weight loss of control samples was $15.64 \%$. At that time, the commercial value of 'Sanh' orange fruits had decreased due to the fruits started to get softer. Segments of the navel orange were difficult to separate which were bland in flavor. Orange peel turned into color yellow and wrinkled (data not shown in this research). Therefore, weight loss percentage was unacceptance (more than 15\%) that has been recommended. At the end of the storage period, the percentage weight loss of wrapped PVC fruits was the lowest $(15.10 \%)$ compared to those ones. The control sample (CT) was totally damaged $(100 \%)$, coated chitosan fruits was the highest

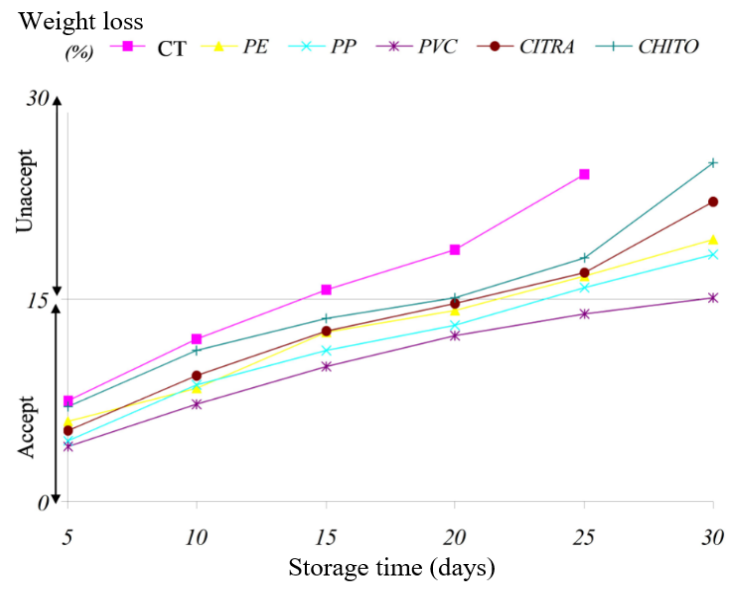

Figure 1. Effect of using films coating on the weight loss of 'Sanh' oranges during storage.

weight loss $(25.10 \%)$, followed by coated Citra Shine $(22.24 \%)$. Overall, the unacceptable percentage weight loss was observed in the wrapped PP samples (over 15\%). The respiratory process enhances dehydration in fruits, increase water loss, the ripening process happens quickly, and thereby the decline in fruit quality. These findings are in agreement with other studies described a direct correlation between the internal gas modification of coated fruit and coating thickness, which depends on solid content and density of the coating formulation (Navarro-Tarazaga \& PerezGago, 2006). According to Nguyen et al. (2005), they treated 'Sanh' orange with $4-6 \%$ potassium sorbate concentrations combined with $1 \%$ chitosan film only reduced the incidence of $4 \%$ weght loss after one month of storage at $4-6^{0} \mathrm{C}$. Simultaneously, the gel system of aging cells also has the tendency to lose water in fruits of water, so the evaporation rate increased significantly.

\subsection{Decay incidence}

After 15 days of storage, 'Sanh' orange was against the postharvest decay (Table 1) due to the fact that fruits were treated with chlorine before storage, reduced the incidence of fruit rot. Hence, the anti-fungal activities by using chlorine $(0.04 \%)$ in 5 minutes killed the funguses on the surface of 'Sanh' orange, thus limiting harmful fungus. At the room temperature storage, 'Sanh' orange was damaged after the next 15 days of storage except for PVC, Citra Shine and chitosan samples that had lower decay percentage. How- 
ever, there was a statistically significant difference at $1 \%$ in the values of incidence of fruit rot between the wrapped and unwrapped fruits, the highest decay incidence was the control sample $(16.60 \%)$.

After 30 days of storage, the whole samples increased the decay incidence and had a statistically significant difference at $P<0.01$, PP samples were the highest incidence of damage (55.80\%), PVC samples (10.80\%) and Citra Shine samples $(12.90 \%)$ were the lowest. The high incidence of fruit rot does not satisfy conditions of preservation process due to several direct impacts on the quantity and the quality of fruit. Decay due to natural infection during the whole storage was relatively low as fruit were sanitized with a fungicide. The films and coatings can suspend decay by reducing senescence, which causes more susceptibility to pathogenic infection in produce due to damage of cellular or tissue integrity (Tanada-Palmu \& Grosso, 2005). After 30 days of storage, the whole samples had the higher decay incidence (over 10\%), the highest was PP samples (55.80\%), the lowest was PVC samples (10.80\%).

\subsection{The rate of stem loss}

The rate of stem loss did not occur afer the first 15 days of storage; however, in the next 15 storage days, this rate was noted in many samples and had a statistically significant difference at $P<0.01$ (Table 2). After 20 days of storage, the shedding of fruit began to appear in the whole samples, the highest was still PP samples $(24.60 \%)$, this rate was quite high in the control samples $(16.10 \%)$, the lowest was PVC samples $(3.70 \%)$. The rate of stem loss continued to increase over the storage process until the 30th day, all most samples appeared this problem, PP samples had the highest rate $(44.80 \%)$, Citra Shine samples (16.10\%) and the lowest was PVC samples $(8.20 \%)$.

\subsection{Color}

Overall, the colourful alteration $(\triangle \mathrm{E})$ of the shell increased with the stored period and after each time of observation, and had statistically significant difference between the samples varies. The results in Table 3 showed that $\triangle \mathrm{E}$ between treatments were statistically different at room temperature from the $5^{\text {th }}$ day to the $30^{\text {th }}$ day during the storage period. After 25 days of storage, the colourful alteration $(\triangle \mathrm{E})$ of control samples (50.69) and PE samples (51.20) increased meaningfully and were statistically significant difference at $5 \%$. The colourful change $(\triangle \mathrm{E})$ of control samples and PE samples were larger than the other's. It may be due to dehydration in fruits, respiratory process, and ripening process occurs rapidly, and thereby chlorophyll content declines quickly. Additionally, appearance refers to color, glossiness, and absence of visual defects on food products. During their storage, food products are susceptible to oxidation reactions and enzymatic browning, which cause undesired color changes and moisture loss that lead to size shrinkage and gloss reduction. Skin blemishes may be caused by exposure to pests, microbial and mechanical damages. Applying films coating or packaging prior to the storage can inhibit this deleterious effects. Moreover, appropriate coating components can enhance the gloss and visual attractiveness of the food product. On the 30th day of storage, maximum colourful alteration value was observed in PE samples (52.77), whereas the minimum values were noted in Citra Shine samples (49.55), and followed by chitosan samples (49.6), and PVC samples (50.51). The lowest $\triangle \mathrm{E}$ values was alteration of three treatments (green to yellow) was slower than the other treatments.

\section{5. $\mathrm{pH}$ value}

Data in Table 4 shows the results of $\mathrm{pH}$ values of 'Sanh' orange that increased gradually as storage time progressed. However, during the 30 days of storage, $\mathrm{pH}$ values of the whole treatments was not statistically significant difference. So, using films coating to prolong the shelf-life 'Sanh' orange did not concern $\mathrm{pH}$ values. In contrast, according to Fereshteh et al. (2017), fruit juice pH increased during storage as was expected with the decline in fruit acidity. The different coatings evaluated in Fereshteh's study showed different effects on $\mathrm{pH}$. These results are similar to found by Baldwin et al. (1999) who observed that $\mathrm{pH}$ value depends on the type of coating. Changes in $\mathrm{pH}$ might be due to the effect of treatment on the biochemical condition of the fruit. The metabolic activity particularly rate of respiration could be affected by the coating solution (Jitareerat et al., 2007). 
Table 1. Effect of using the coating on the decay incidence of 'Sanh' oranges during storage

\begin{tabular}{lcccc}
\hline & \multicolumn{4}{c}{ Storage time (days) } \\
\cline { 2 - 5 } & 15 & 20 & 25 & 30 \\
\hline $\mathrm{CT}^{1}$ & $(16.60 \pm 1.32)^{\mathrm{a}}$ & $(21.60 \pm 1.09)^{\mathrm{b}}$ & $(42.80 \pm 2.53)^{\mathrm{a}}$ & Decayed \\
$\mathrm{PE}^{1}$ & $4.30 \pm 0.21^{\mathrm{c}}$ & $6.90 \pm 0.87^{\mathrm{d}}$ & $(15.90 \pm 0.45)^{\mathrm{c}}$ & $(33.30 \pm 1.12)^{\mathrm{b}}$ \\
$\mathrm{PP}^{1}$ & $8.60 \pm 0.35^{\mathrm{b}}$ & $(25.80 \pm 1.21)^{\mathrm{a}}$ & $(43.10 \pm 3.81)^{\mathrm{a}}$ & $(55.80 \pm 4.21)^{\mathrm{a}}$ \\
$\mathrm{PVC}^{1}$ & $0.00 \pm 0.00^{\mathrm{d}}$ & $4.00 \pm 0.35^{\mathrm{e}}$ & $7.10 \pm 0.70^{\mathrm{d}}$ & $(10.80 \pm 0.67)^{\mathrm{d}}$ \\
$\mathrm{CITRA}^{1}$ & $0.00 \pm 0.00^{\mathrm{d}}$ & $4.10 \pm 0.29^{\mathrm{e}}$ & $8.60 \pm 0.85^{\mathrm{d}}$ & $(12.90 \pm 0.35)^{\mathrm{c}}$ \\
$\mathrm{CHITO}^{1}$ & $0.00 \pm 0.00^{\mathrm{d}}$ & $8.50 \pm 0.16^{\mathrm{c}}$ & $(17.40 \pm 0.63)^{\mathrm{b}}$ & $(32.50 \pm 1.34)^{\mathrm{b}}$ \\
\hline $\mathrm{F}$ & $* *$ & $* *$ & $* *$ & $* *$ \\
$\mathrm{CV}(\%)$ & 4.64 & 5.35 & 2.57 & 6.83 \\
\hline
\end{tabular}

${ }^{\mathrm{a}-\mathrm{e}}$ Values on the same column with different letters are not significantly different from the Duncan test, **statistically significant difference at $P<0.01$. Values in parentheses (): Analyze the rest values.

${ }^{1} \mathrm{CT}$ : Control (uncoated), PE: Polyethylene, PP: Polypropylene, PVC: Polyvinyl chloride, CITRA: Citra shine, CHITO: Chitosan.

Table 2. Effect of using the coating on the rate of stem loss of 'Sanh' oranges during storage

\begin{tabular}{lcccc}
\hline & \multicolumn{4}{c}{ Storage time (days) } \\
\cline { 2 - 5 } & 15 & 20 & 25 & 30 \\
\hline $\mathrm{CT}^{1}$ & $(10.20 \pm 0.45)^{\mathrm{a}}$ & $(16.10 \pm 1.02)^{\mathrm{b}}$ & $(18.90 \pm 0.20)^{\mathrm{b}}$ & $(22.10 \pm 1.07)^{\mathrm{c}}$ \\
$\mathrm{PE}^{1}$ & $6.30 \pm 0.32^{\mathrm{b}}$ & $11.50 \pm 1.30^{\mathrm{c}}$ & $(13.20 \pm 0.37)^{\mathrm{d}}$ & $(16.10 \pm 0.88)^{\mathrm{d}}$ \\
$\mathrm{PP}^{1}$ & $10.60 \pm 0.68^{\mathrm{a}}$ & $(24.60 \pm 1.12)^{\mathrm{a}}$ & $(32.70 \pm 2.08)^{\mathrm{a}}$ & $(44.80 \pm 3.25)^{\mathrm{a}}$ \\
$\mathrm{PVC}^{1}$ & $0.00 \pm 0.00^{\mathrm{c}}$ & $3.70 \pm 0.25^{\mathrm{e}}$ & $6.60 \pm 0.51^{\mathrm{e}}$ & $(8.20 \pm 0.27)^{\mathrm{e}}$ \\
$\mathrm{CITRA}^{1}$ & $6.40 \pm 0.37^{\mathrm{b}}$ & $10.20 \pm 0.85^{\mathrm{cd}}$ & $(16.10 \pm 1.54)^{\mathrm{c}}$ & $(16.10 \pm 0.75)^{\mathrm{d}}$ \\
$\mathrm{CHITO}^{1}$ & $0.00 \pm 0.00^{\mathrm{c}}$ & $9.60 \pm 0.35^{\mathrm{d}}$ & $(18.10 \pm 0.51)^{\mathrm{c}}$ & $(24.50 \pm 1.10)^{\mathrm{b}}$ \\
\hline $\mathrm{F}$ & $* *$ & $* *$ & $* *$ & $* *$ \\
$\mathrm{CV}(\%)$ & 8.66 & 5.39 & 4.16 & 5.44 \\
\hline
\end{tabular}

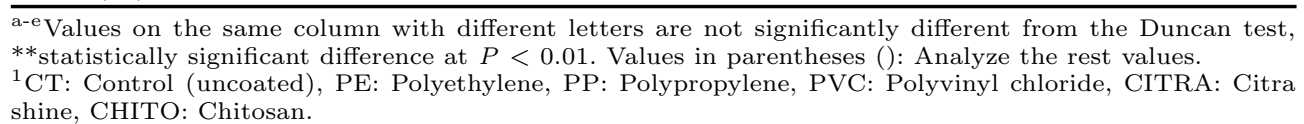

\subsection{Total soluble solids}

'Sanh' orange is a non-climacteric fruit, and they tend to decrease in total soluble solids in fruits, so ${ }^{\circ}$ Brix value changes primarily due to dehydration in fruits. After 5 days storage, the whole values of total soluble solids (TSS) of 'Sanh' orange between the most treatments was not significantly different (Table 5). However, after 10 days of storage, ${ }^{0}$ Brix values of the whole treatments were statistically significant difference at $P<0.05$ and $P<0.01$ on the $15^{\text {th }}, 20^{\text {th }}$, $25^{\text {th }}$ and $30^{\text {th }}$ days. ${ }^{\circ}$ Brix values of the control samples increased rapidly after 20 days of storage because respiration process was strong and the ripening process occurred quickly. Fruit TSS increased during storage due possibly to the cell wall disassembly (Cordenusi et al., 2005), and the enhancement in dry matter due to the reduction in the fruit water content during storage (Dhall, 2013). These findings are in agreement with re- sults of researchers with other cultivars of citrus fruit such as 'Tacle' and 'Clara' mandarin (Rapisarda et al., 2008) as well as 'Ougan' and 'Hongju' mandarin (Ye et al., 2000). Moreover, the degradation of pectin, cellulose, and hemicellulose from cell walls within fruit segments might result in releasing soluble components which could have a direct effect on TSS (Iglesias \& Echeverria, 2009). It has been shown that solubilization of the cell wall constituents under the effect of glucosidase and galactosidase present in citrus fruit, might have contributed to the increase in TSS levels (Iglesias \& Echeverria, 2009). After 30 days of storage, ${ }^{\circ}$ Brix value tends to decrease in the whole samples, may be because of the activity of respiratory process that consumed the most total soluble solids stored. ${ }^{0}$ Brix values of PVC samples tends to increase slightly, because using PVC film wrapped 'Sanh' orange at room temperature that slows down the dehydration process and consumes more total soluble solids stored than other 

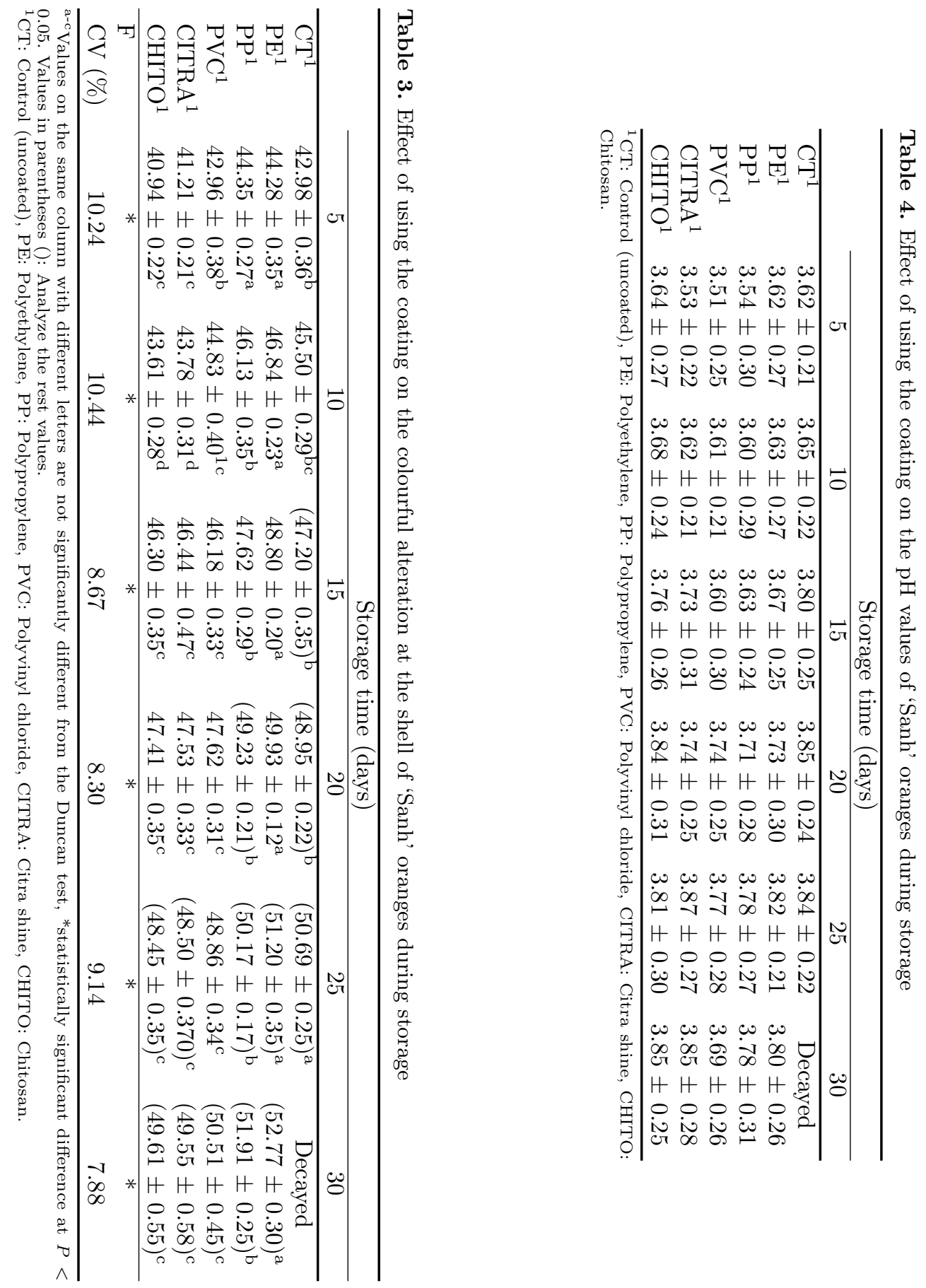

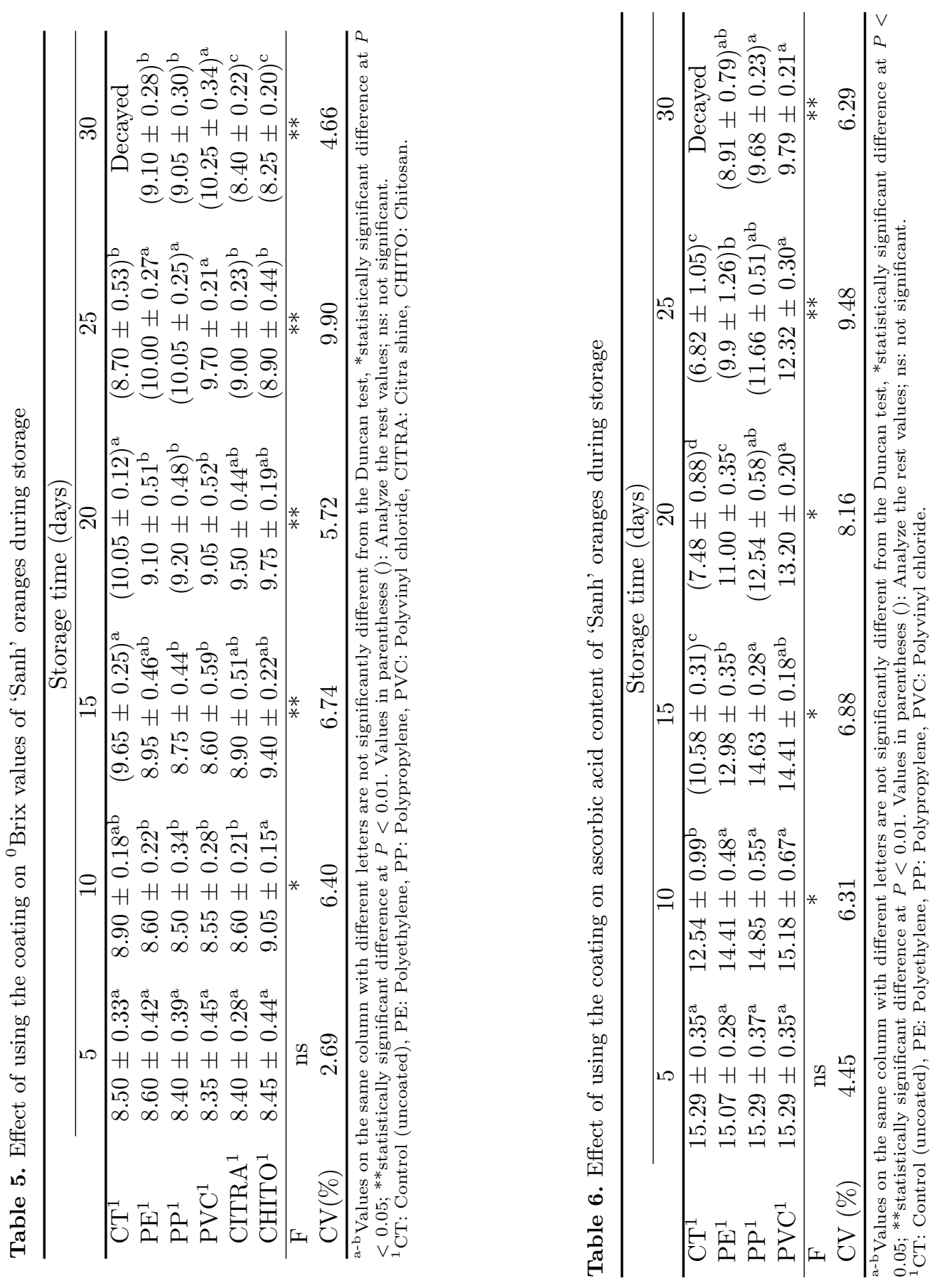
samples.

\subsection{Ascorbic acid content}

The main quality indexes of citrus fruit include TSS and ascorbic acid content. They were dynamically changed during postharvest storage (Ye et al., 2000). The ascorbic acid content in both wrapped and unwrapped fruits decreased gradually as storage period (Table 6 ). After 5 days of storage, the content of ascorbic acid of all samples was still quite high and there is no statistically significant difference. Ascorbic acid content gradually decreased in both treated and untreated fruit during storage. Khaliq et al. (2016) reported that mango fruit coated with gum arabic enriched with calcium chloride showed similar results. After 30 days of storage, ascorbic acid content in all samples had a statistically significant difference at $1 \%$. At the end of the storage period, PP samples (9.68 mg/100 g), PE samples (8.91 $\mathrm{mg} / 100 \mathrm{~g}$ ) and PVC samples $(9.79 \mathrm{mg} / 100 \mathrm{~g})$ had a relatively high value of ascorbic acid compared to the control, chitosan, and Citra Shine samples. The results show that the utilization of synthetic films coating on fruits such as PP, PE, $\mathrm{PVC}$ is the most effective in preventing ascorbic acid losses. The differences reported might indicate that ascorbic acid loss during storage depends on the type of coating. Ascorbic acid plays an important role as an antioxidant and declines the oxidative stress (Fereshteh et al., 2017). The higher ascorbic acid content in treated fruit could be related to strengthening the defence system and maintaining the fruit quality without deterioration during storage condition (Khaliq et al., 2016).

\section{Conclusions}

Comparative analysis on the effects of several coating films and room storage conditions on the quality and the shelf-life of 'Sanh' orange, as observed in the present study, reveals that the utilization of wrapped PVC and storage at room temperature $\left(30 \pm 2^{0} \mathrm{C}\right)$ was the best treatment for maintaining the quality and extending the shelf-life of 'Sanh' orange over other treatments or control, which was exhibited by the least weight loss percentages (13.91\%), decay incidence, and the rate of stem loss, lower total soluble solids, higher ascorbic acid (12.32 mg/100 g), $\mathrm{pH}$ (3.77), maintained stable TSS values $(9.7 \%)$ after 25 days of storage.

\section{References}

AOAC (AOAC International). (2004). Official methods of Analysis. The Association of official chemists $18^{\text {th }}$ ed. Arlington, USA.

Baldwin, E. A., Nisperos-Carriedo, M., Shaw, P. E., \& Burns, J. K. (1995). Effect of coating and prolonged storage conditions on fresh organe flavor volatiles, degree brix and ascorbic acid levels. Journal of Agricultural and Food Chemistry 43(5), 1321-1331.

Baldwin, E. A., Burns, J. K., Kazokas, W., Brecht, J. K., Hagenmaier, R. D., Bender, R. J., \& Pesis, E. (1999). Effect of two edible coatings with different permeability characteristics on mango (Mangifera indica L.) ripening during storage. Postharvest Biology and Technology 17(3), 215-226.

Bramlage, W. J. (1986). Physiological effects of waxingon apples. Proceedings of the Annual Meeting of Massachusetts Fruit Growers' Association (111-113). Massachusetts, USA: Massachusetts Fruit Growers' Association Inc.

Cordenusi, B. R., Genovese, M. I., Do Nascimento, J. R. O., Hassimoto, N. M. A., Dos Santos, R. J., \& Lajolo, F. M. (2005). Effects of temperature on the chemical composition and antioxidant activity of three strawberry cultivars. Food Chemistry 91(1), 113-121.

Dhall, R. (2013). Advances in edible coatings for fresh fruits and vegetables: a review. Critical Reviews in Food Science and Nutrition 53(5), 435-450.

Drake, S. R., \& Nelson, J. W. (1990). Storage quality of waxed and non-waxed "Delicious" and "Golden Delicious" apples. Journal of Food Quality 13(5), 331-341.

Fereshteh, K., Asghar, R., \& Hosseini, S. H. H. (2017). Shellac, gelatin and Persian gum as alternative coating for orange fruit. Scientia Horticulturae 225, 22-28.

Hagenmaier, R. D., \& Shaw, P. E. (2002). Changes in volatile components of stored tangerines and other specialty citrus fruits with different coatings. Journal of Food Science 67(5), 1742-1745.

Iglesias, I., \& Echeverria, G. (2009). Differential effect of cultivar and harvest date on nectarine colour, quality and consumer acceptance. Scientia Horticulturae 120(1), 41-50.

Jitareerat, P., Paumchai, S., \& Kanlayanarat, S. (2007). Effect of chitosan on ripening enzymatic activity: and disease development in mango (Mangifera indica L.) fruit. New Zealand Journal of Crop and Horticultural Science 35(2), 211-218.

Khaliq, G., Muda Mohamed, M. T., Mohd Ghazali, H., Ding, P., \& Ali, A. (2016). Influence of gum arabic coating enriched with calcium chloride on physiological: biochemical and quality responses of mango (Mangifera indica L.) fruit stored under low temperature stress. Postharvest Biology and Technology 111, 362-369. 
Navarro-Tarazaga, M. L., \& Perez-Gago, M. B. (2006). Effect of edible coatings on quality of mandarins cv. Clemenules. Proceedings of the Florida State Horticultural Society 119, 350-352.

Nguyen, M. V., Chau, A. T. D., Nguyen, P. N. M., Phan, D. T. A., \& Lam, H. T. V., (2005). Effects of temperature on storage and quality of 'Sanh' orange fruits. National workshop on Citrus, mango and pineapple VLIR-IUC CTU - Scheme R.2-Fruit trees (135-140). Agriculture Publishing House.

Porat, R., Weiss, B., Cohen, L., Daus, A., \& Aharoni, N. (2004). Reduction of postharvest rind disorders in citrus fruit by modified atmosphere packaging. Postharvest Biology and Technology 33(1), 35-43.

Rapisarda, P., Bellomo, S., Fabroni, S., \& Russo, G. (2008). Juice quality of two new mandarin-like hybrids (Citrus clementina Hort. ex Tan $\mathrm{x}$ Citrus sinensis L. Osbeck) containing anthocyanins. Journal of Agricultural and Food Chemistry 56(6), 2074-2078.
Tanada-Palmu, P. S., \& Grosso, C. R. (2005). Effect of edible wheat gluten-based films and coatings on refrigerated strawberry (Fragaria ananassa) quality. Postharvest Biology and Technology 36(2), 199-208.

Trout, S. A., Hold, E. G., \& Sykes, S. M. (1952). Effect of skin coatings on the behavior of apples in storage. Australian Journal of Agricultural Research 4(1), 5781.

Wilson, C. L., \& Wisniewski, M. E. (1989). Biological control of postharvest diseases of fruits and vegetables: an emerging technology. Annual Review of Phytopathology 27, 425-441.

Ye, M. Z., Chen, Q. X., Xu, J. Z., Xu, X. Z., Zhao, M., \& Xia, K. S. (2000). Some physiological changes and storability of citrus fruits during storage. Plant Physiology Communications 36, 125-127. 